\title{
Telecommunications Policy: \\ Alliances, Interconnection, and Universal Service
}

\author{
By: Sanford V. Berg and Mark A. Jamison
}

Public Utility Research Center

University of Florida 



\title{
Telecommunications Policy: Alliances, Interconnection, and Universal Service*
}

\author{
By Sanford V. Berg and Mark A. Jamison \\ Public Utility Research Center \\ University of Florida
}

Any survey of such a dynamic industry as telecommunications is bound to be idiosyncratic-reflecting the particular tastes and interests of the reviewers. We do not apologize for selectivity, but wish to acknowledge that another team could review developments in telecommunications policy and present a very different set of observations. We focus on global alliances, interconnection, and universal service. These three issues illustrate how basic industry conditions (mediated by regulatory regimes) lead to market structures. Market structure, particularly the number of firms and entry conditions, influences corporate behavior. The resulting market performance is a key factor dete ining public policy initiatives. Legal changes, such as privatization or deregulation, create new constraints and/or open up commercial opportunities. Since policy is endogenous, identifying the impacts of a particular policy on performance is difficult in practice.

\section{Forces Shaping Telecommunications Policy ${ }^{1}$}

Telecommunications regulators face significant challenges. Often telephony was under government ownership - so price structures were often designed to subsidize particular customer groups. When costs exceeded revenues, vertically integrated public enterprises sought capital from the government. Fiscal pressures often limited transfers to suppliers, leading to declines in service quality and low penetration rates. In response to this situation, private participation in the provision of infrastructure services has increased dramatically, as developing countries are restructuring public enterprises. Corporatization separates enterprises from government agencies, putting them on a commercial basis. In addition, many entities have been or are in the process of being privatized. In either case, some government oversight responsibilities remain.

A key concern is with the exercise of market power. Portions of infrastructure industries are natural monopolies. That is, a single supplier is the least cost arrangement for providing the service (such as electricity transmission or distribution). However, unregulated monopolies tend to price so that excessive returns are obtained. Prices which are greater than incremental cost do not promote allocative efficiency, so some form of intervention is called for. Beyond efficiency concerns are concerns for fairness, as consumers face high prices set by the monopolist, with the above-normal profits going to shareholders. In the case of public ownership, excessive returns

\footnotetext{
- This paper draws upon a number of PURC Working Papers. The views expressed here do not necessarily represent those of PURC sponsors.

1. Portions of this section are based upon Berg 1998.
} 
may go to the Treasury, though incentives for cost containment are not be strong, so potential rents may be dissipated.

Regulation is often characterized as a form of taxation. Coalitions of suppliers and demanders promote particular price structures so that they benefit from the institutional arrangements. In the case of a natural monopoly, sustained investment may require a regulatory contract -limiting opportunistic behavior by regulators after the firm has made substantial investments (which are now sunk). In addition, entry restrictions mean that prices do not need to track costs. A system of implicit taxes and subsidies develops. New technologies that promote entry (or self-production) can make those prices unsustainable.

Of course, part of the initial problem often stemmed from keeping prices too low, at politically popular levels. However, such prices are not sustainable unless taxpayers are willing to subsidize the consumption of telephone services. The concern over access is better addressed by targeted subsidies rather than artificially holding a price below cost. Of course, the transition to cost-based prices represents a political problem as suppliers are placed on commercial footings.

As will be described shortly, the basic technological and demand conditions leading to natural monopoly can justify government oversight, which requires the development of new regulatory institutions. The PURC/ World Bank International Training Program on Utility Regulation and Strategy represents one vehicle for the sharing of experience and expertise in the creation of agencies that constrain monopoly power and promote competition where it is feasible. The new regulatory agencies are important to both consumers and investors, as decisions are insulated from politicians whose time horizons only extend to the next election. We observe nations attempting to create stable, credible, and independent regulatory framework. Both regulators and infrastructure managers have a stake in developing a systematic, transparent, and independent process. Once they understand key principles, decision-makers are better able to develop policies that promote credibility for investors, legitimacy for consumers, and efficiency in the economy.

Links between government infrastructure policies and realized performance are not fully understood. The task of identifying these links is complicated by many factors, including the numerous intricate relationships among key variables. To illustrate, just as infrastructure policy affects industry performance, industry performance, in turn, affects future infrastructure policy. Any cross-sectional comparisons need to incorporate endogeneity of regulatory policies. Furthermore, key economic, political, and institutional parameters affect directly both the governments' choice of infrastructure policy and realized performance in the industry.

The task of assessing the merits of specific infrastructure regulatory policies is complicated by the intricate relationship among key variables. Some of these relationships are depicted in Figure 1 (Causes and Effects of Infrastructure Policies). The four boxes to the far left in Figure 1 represent some of the many factors that influence a governments' choice of infrastructure policy. "Industry conditions" include those factors that affect industry demand (e.g., population, income, and education) and those that affect industry supply (e.g., production technologies, operating practices, and factor prices). "General economic conditions" include a nations' employment, 


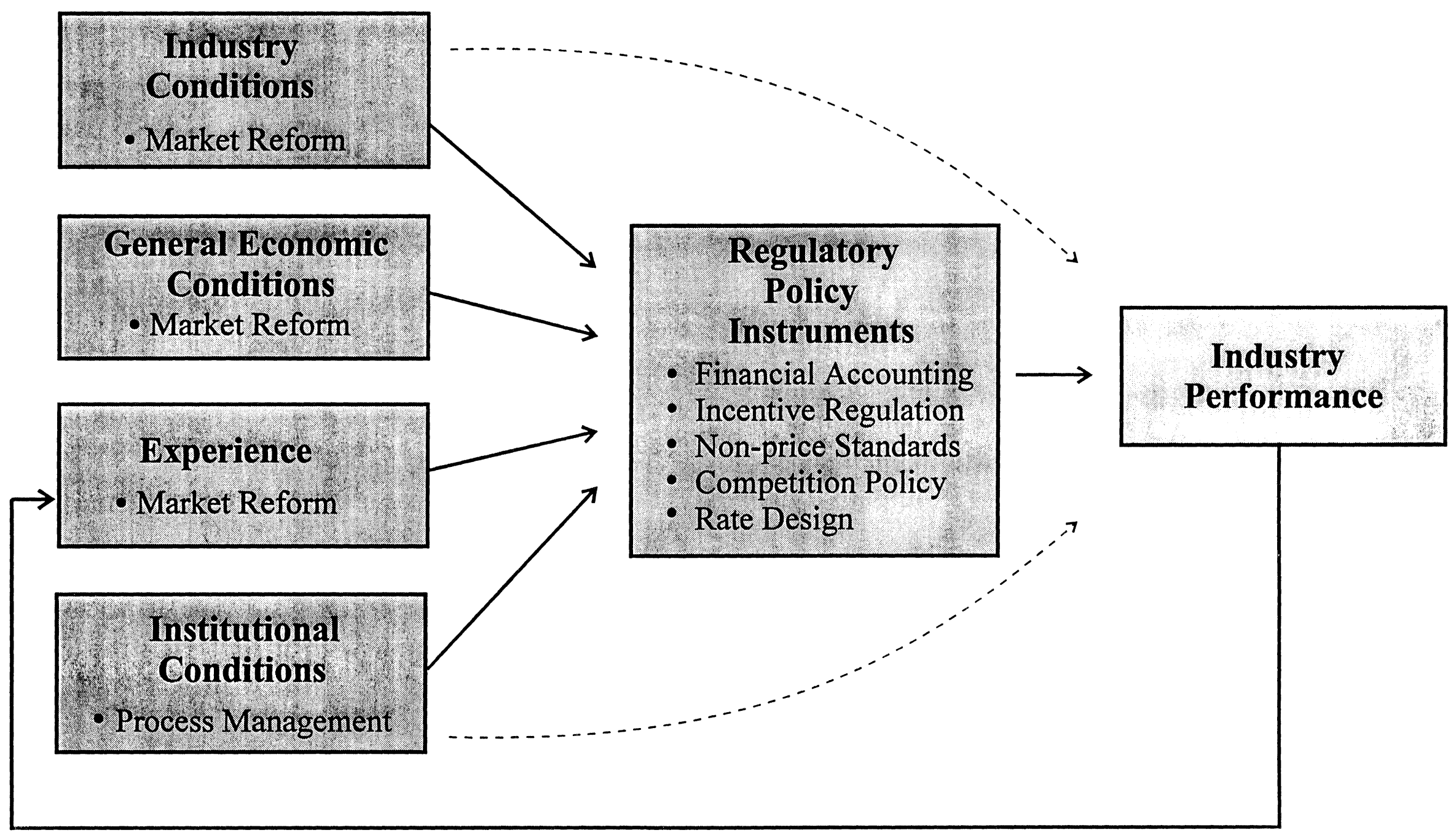

Figure 1. Regulation and Industry Performance 
savings, and inflation rates, as well as the strength, stability, and diversity of its economy, its balance of trade, and the strength and stability of its capital markets.

The "Experience" box in Figure 1 refers to local, national, and international experience with infrastructure regulatory policies. Industry performance under past regulatory regimes (both in absolute terms and relative to the corresponding performance in other jurisdictions) often influences the choice of future policy. ${ }^{2}$ The "Institutional Conditions" box in Figure 1 incorporates a number of factors:

strength and independence of a country's judicial system, nature and stability of the country's political system, autonomy of regulatory officials, resources at their disposal, and nature and historic enforcement of property rights and laws that pertain to infrastructure development policy.

These factors affect the ability of regulators to make credible long-term commitments to private investors and to pursue independent policies. ${ }^{3}$

The solid arrows in Figure 1 depict the fact that these (and other) factors affect directly a government's choice of infrastructure regulatory policy, and that the chosen policy, in turn, affects industry performance. The broken arrows in Figure 1 reflect the fact that many of the same factors that influence policy choice will also affect observed industry performance directly. For instance, under any infrastructure regulatory policy, realized production costs will generally be affected both by the prevailing production technology and by perceptions of the government's tolerance for substantial earnings. Other relevant arrows have been omitted from Figure 1 in order to simplify the diagram. For instance, industry conditions often influence and are influenced by general economic conditions. In addition, current industry performance affects both future industry conditions and experience that is relevant for future decisions.

Figure 2 provides a more detailed look at how industry infrastructure policy affects market structure, constrains the behavior of service providers, and affects industry performance. Fundamental economic factors determine the structure of an industry. These "Basic conditions" include production technologies and consumer preference patterns. Factors influencing supply and demand determine the efficient configuration of the industry. Telecommunications restructuring is an issue in most nations, due to mergers, new entry, and developments in related markets such as cellular or PCS. Because of technological changes and changes in public attitudes towards government intervention, markets are experiencing changes in the basic conditions which influence them. These economic forces for change are powerful, inevitable, and highly disruptive.

2. See Berg and Jeong (1991) for some relevant empirical evidence. Berg and Foreman (1996) outline some of the feedbacks in the process.

3. Levy and Spiller $(1994,1996)$ document the importance of these and other institutional differences among countries. The authors also provide useful guidance on how to measure these differences. 
Note the primary flow of causation in traditional utilities. Basic conditions determine structure. Structure influences pricing behavior, and the resulting industry performance is an outcome of the economic processes at work. Of course, the traditional utility market structure, no entry, single supplier, vertical integration, and homogenous output, was heavily conditioned by regulation and public ownership--both arose to constrain monopoly power.

Basic conditions facing an industry influence the number and size distribution of suppliers which are feasible in an industry. As noted earlier, the traditional features comprising the structure, behavior, and performance of public utility industries involve important linkages. Causation runs from the basic conditions to industry structure (entry conditions, number of firms, degree of vertical integration and product differentiation). Industry structure determines, in turn, the behaviors likely to be observed (prices, promotion, research and development, production process changes, and new service introductions). The market outcomes can then be described in terms of performance criteria (profitability, efficiency, innovation, and meeting other social objectives). Clearly there are feedbacks in this process--for example, high levels of R\&D can lead to innovations which affect the production technologies and entry conditions.

Traditional telecommunications regulation (particularly as developed in the U.S.) influenced the structure of industries and limited the range of behaviors observed. ${ }^{4}$ Regulatory rules defined markets, constrained entry, and facilitated vertical integration. Thus, cost-based rate of return on rate base regulation (ROR) was designed to enable the firm to earn a fair return on its investment while protecting customers from monopoly prices. Complex cost allocation procedures resulted in the sharing of capacity costs across customer groups, over markets for different services, and between political jurisdictions (state regulation of local prices vs. federal control of interstate calls). Postage stamp (uniform) pricing was sometimes utilized, despite cost differences in serving various locations or customer groups.

Thus, regulation influenced the number of suppliers in various markets and the prices facing customer groups. However, the optimal configuration of firms in an industry depends on underlying basic conditions that change over time. For example, economies from vertical integration, also called economies of sequence, change. Vertical relationships remain in telecommunications in some nations today--while in others, vertical disintegration has occurred. Similarly, there can be changes in the savings associated with producing several products (instead of specializing in a single product). These economies of scope determine whether multiproduct firms are least-cost providers of services. The familiar term, economies of scale, refers to declining average costs as output increases. All three economies characterized the production technologies of infrastructure industries in the past.

4. The activities of regulators are difficult to model. Warrick Smith (1997 a) identified at least nine potential roles for regulators: technician, political analyst/strategist, advocate, detective, prosecutor, judge, negotiator, educator, and manager. Not all of these roles can be performed simultaneously, but the listing illustrates the multi-faceted nature of regulation. In addition, new institutions encounter the difficulty of reconciling independence with accountability. Furthermore, the design of regulatory systems requires a careful balance between rigidity and flexibility. The former promotes predictability in decision-making and supports keeping commitments. The latter (the exercise of discretion) can facilitate adaptation to changing economic conditions. 


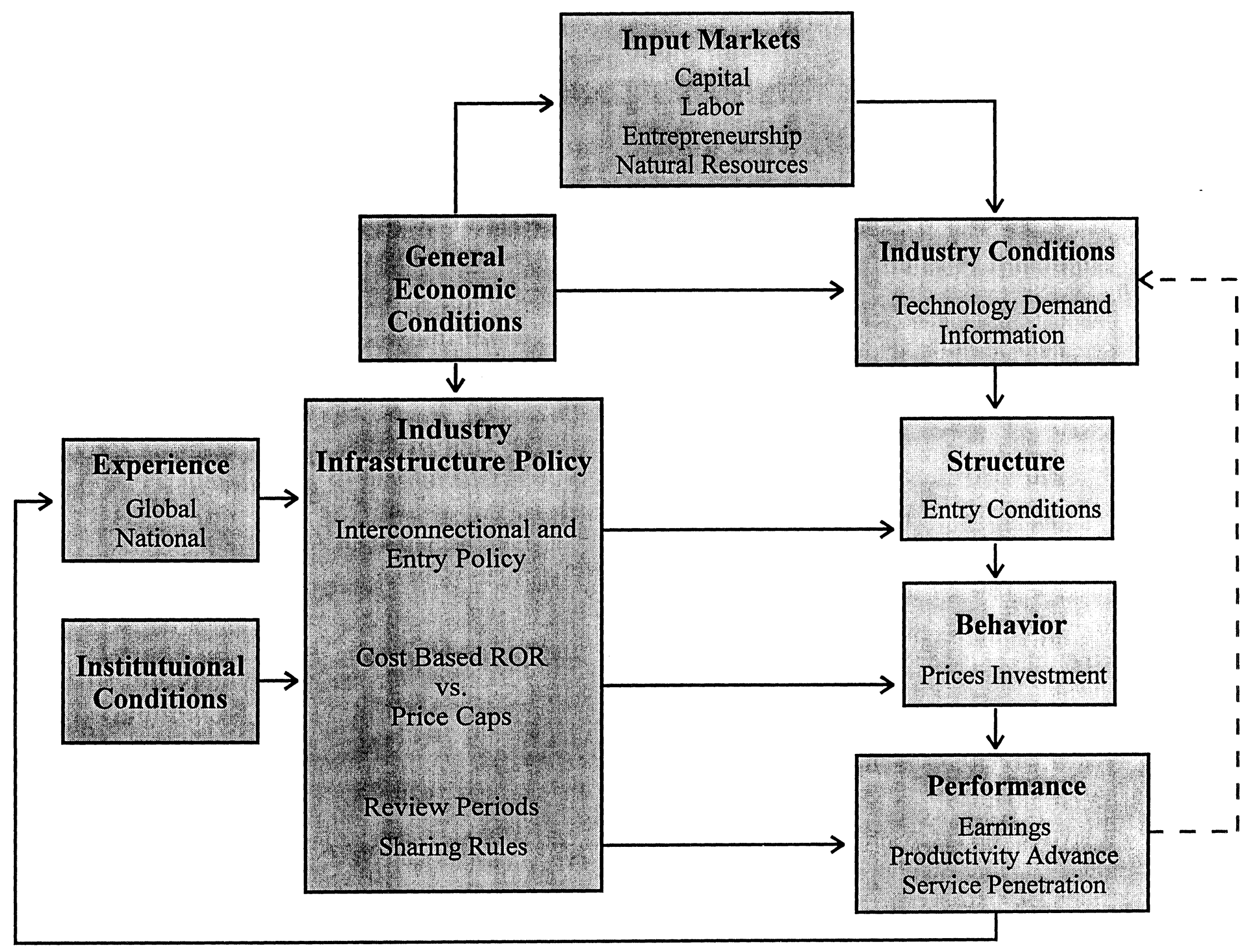

Figure 2. Determinants and Impacts of Industry Infrastructure Policy 
as letting customers own the telephone wires in their houses took years of legal and political wrangling to implement.

Finally with the Telecommunications Act of 1996 in the US and many other policy events around the world, economic reality overcame political inertia and open markets becoming official government policy. Of course, the reality of significant legislation is that key issues were left unresolved--leaving it to the courts and regulatory agencies to work out the meaning of the legalese in the legislation. Despite the on-going battles, the real economics of the business is beginning to pressure business decision-makers. The once engineering-dominated voice telephone companies are looking for ways to remake themselves. In this environment, successful companies will be market driven and will offer a flexible array of voice, data, and video capabilities.

But successfully moving a company from a nearly 100 -year old structure to a business architecture that no one fully understands is no simple task. It involves divesting assets, creating and invading new markets, and combining with other businesses. AT\&T's divestiture of Lucent Technologies and Cincinnati Bell's spinning off its data and billing business are recent examples of companies shedding operations which, while perfectly good businesses, are better off separate from their former companies. Ameritech's entry into cable television, SBC's international investments, and Sprint's creation of a product for global collaboration in multimedia production demonstrate that companies are creating and invading new markets.

According to Ware, these developments suggest that although the expansion of the competitive process has not been rapid, it is real. In the United States, he notes, "The telecommunications industry has not met the unrealistic expectations of some observers that the Act would immediately engender full competition in all telecommunications markets and lower all prices. However, the Act and already strong regulatory, market and technological trends have clearly stimulated substantial and accelerating competition across historically distinct markets. The Interexchange Carriers (IXCs) have entered local markets; cable TV firms, Competive Access Providers and Competitive Local Exchange Carriers (CAPs/CLECs), and even electric utilities are also expanding into local telephony markets; and all firms are seeking to provide more diversified service packages. SNET's entry into the interexchange market in Connecticut demonstrates that the benefits of competition--lower rates and service innovation--will be realized when BOCs are allowed to enter long distance markets." Ware (1998, p. 89).

Some analysts view the mergers among the regional operating companies in the U.S. as signaling a reduction in potential competition. We argue that the acquisitions and alliances are simply another way that companies are recombining assets to reduce costs, differentiate products, and provide end-to-end service. These business realignments can create a more efficient industry that has lower costs, new and better products, and greater global competitiveness. This global competition benefits US customers by creating more choices and increasing the intensity of domestic competition. The reason for this is that global companies have greater incentives and abilities to enter each other's markets.

For example, suppose that regulators had not allowed SBC to leave its 5-state region of Texas, Oklahoma, Kansas, Missouri, and Arkansas. Under this scenario, the primary key to the 
This brief overview of the forces contributing to public policy initiatives is not exhaustive. However, it identifies some key linkages in the process and outlines the feedbacks that complicate analysis. To illustrate some patterns emerging in public policy, we focus on three areas: alliances among suppliers, interconnection pricing, and universal service obligations

Alliances and Market Structure: Mergers and strategic alliances alter the size distribution of firms in the industry. They also enable some technologies to be applied more quickly than otherwise would be the case. So they can raise entry barriers--by increasing the scale required to entry a market. Alternatively, they can facilitate entry, by enabling new players to be credible suppliers in emerging markets. Their stability is questionable, given experiences to date.

Interconnection Pricing affecting Structure and Conduct: Interconnection prices affect entry conditions--a key aspect of industry structure. These prices may be determined by public policy mandates and/or reflect negotiated outcomes. In either case, the terms and conditions of interconnection affect the level and structure of telecommunications prices.

Universal Service as a Dimension of Performance reflecting Prices: Since universal service obligations (USOs) are stated policy objectives in most countries, the lack of basic service penetration or unavailability of advanced services to some customers raise policy issues. USOs generally take the form of government requirements to charge sub-competitive, non-cost covering prices in certain markets, ostensibly to further social objectives.

After discussing these three topics, we conclude with observations regarding the challenges facing both regulators and executives.

\section{Global Alliances and Market Structure ${ }^{5}$}

Many of the criticisms that the current wave of telecommunications mergers and alliances have drawn are unjustified. Some regulators and pundits view these as only decreasing competition and harming consumers. In fact, just the opposite may be true. The mergers of SBC-AmeritechSNET, Bell Atlantic-GTE, MCI-World-Com, and AT\&T-TCI (with an alliance with BT) can be pro-competitive. Telecommunications companies are not simply merging because they subscribe to the "you-gotta-be-big-to-compete" view. They are responding to a seismic shift in business economics, customer demands, and government rules. Being the best will often depend on combining with other companies.

For decades, US telecommunications companies have conformed to antiquated market restrictions and business practices. Even though these restrictions and practices came from turnof-the-century technological and political constraints that were outdated even before the Great Depression, government regulation kept companies from making significant changes in their products, markets, or businesses. Over the years, policy-makers have delayed or squashed innovations that threatened how the state PUCs and the FCC share authority, how they divide money between their jurisdictions, how money flows from urban to rural customers, or how nearby television, radio, computer, and publishing markets operate. Even something as simple

5. Portions of this section are excerpts from Jamison (1998d). 
As potential entrants seek access to existing facilities, fundamental regulatory issues arise related to efficiency and incentives to invest in new facilities. Recent PURC research on interconnection (Jamison, 1998c) found that prices and terms for interconnecting with incumbents have been the most controversial interconnection issues. Prices are controversial because they affect profitability and the development of competition. In general, higher interconnection prices are thought to favor incumbents because higher prices preserve or enhance incumbents' revenue streams and raise entrants' costs. Conversely, lower interconnection prices are thought to favor entrants because lower prices mean lower entry costs, allow entrants to use incumbents' networks and pay less than what it would cost the entrants to build their own networks, and decrease incumbents' revenues. Terms for interconnection are controversial because they define what it is that service providers receive when they obtain interconnection with another provider's network. For example, terms that require an entrant to obtain interconnection at a high level in the network hierarchy forces an entrant with an extensive network to purchase more transport and switching than is necessary. ${ }^{7}$

"The interaction between prices and terms is also important to profitability and competition. For example, higher interconnection prices favor incumbents only as long as incumbents are able to exercise market power over the new entrants. Given sufficient time, low entry barriers, and terms that allow interconnection close to customer locations, entrants can bypass uneconomically high prices by building their own networks. On the other hand, lower interconnection prices provide incumbents with an incentive to improve profits by maintaining higher market shares in the more lucrative retail markets. Incumbents may try to maintain these higher market shares by offering only restrictive interconnection terms." (Jamison, 1998c)

To gain a better understanding of how regulators are dealing with this issue, PURC conducted an international survey of interconnection policies. This survey found "that countries are implementing a diverse mix of telecommunications interconnection policies. The US and the UK appear to have the most aggressive policies, tending to adopt policies that would generally be seen as favorable to new entrants. Most countries require service providers to negotiate interconnection agreements, but the number of issues open to negotiation varies considerably. When negotiations fail, most (but not all) countries have the regulator intervene.

"Regarding prices, OECD countries are generally adopting cost-based or cost-oriented standards for prices, but the prices that result from these policies vary greatly. The Baumol-Willig rule has emerged only in New Zealand (although it has since been

7. There are generally three dimensions to interconnection pricing - type of interconnection, classification of service, and type of segment. There are three basic types of interconnection services. With "Termination" service, the provider supplying the interconnection service (Provider $A$ ) takes a call from another provider (Provider B) and terminates the call to one of A's customers. With "Access" service, Provider A allows Provider B's customer to connect to Provider A's network and use this network to reach Provider B. With "Transiting" service, Provider A carries calls between Provider B's network and another Provider's network. There are also four classifications of interconnection services. These are Basic (for traditional voice grade services), Ancillary (e.g., directory inquiries), International, and Signaling (e.g., signaling information to permit mobile customer roaming in different countries). There are three types of segments. If a service provider carries the call between a customer and a point of interconnection in the same numbering area, a local segment charge is applied. If the service provider carries the call between a customer and a point of interconnection within the same interconnect area, the interconnection charge is for a single segment. If the service provider carries the call into another interconnect area, the provider charges for a double segment. 
company's success would have been to ensure that no competitor invaded its region: SBC would have focused all of its resources on that cause. Few competitors would have wasted money trying to invade SBC's markets. Fortunately, this is not what regulators did. As a result, SBC is developing into a global player with a potential for $\$ 43$ billion in annual revenues and 47 million local customers in the US. It is establishing footholds in Bell Atlantic's region, in Europe, and in Latin America, and will probably take steps to solidify footholds wherever SBC's global and national customers need connections.

Of course, Bell Atlantic realizes this and is trying to counter by establishing footholds in SBC's traditional territories. A merger with GTE, which would give Bell Atlantic over $\$ 53$ billion in annual revenues and 61 million local customers in the US, would also give Bell Atlantic such a foothold. Companies with strong footholds in Europe also realize this and are looking for ways to bypass SBC's local infrastructure to secure global customers. For example, the Global One companies Sprint, France Telecom, and Deutsche Telekom, have combined annual revenues of $\$ 78.5$ billion. With 77 million local customers in Europe, and 7.4 million local customers in the US, Global One has local infrastructure in SBC's, Bell Atlantic's, Ameritech's, and BellSouth's regions.

The stability of alliances and joint ventures raises some interesting research issues. Divergent interests among participants can destabilize alliances. If members are primarily concerned about protecting domestic markets (while still responding to the needs of multinational customers), changes in strategies can set centrifugal forces into play. For example, ATT is leaving the Unisource alliance in favor of new arrangements with BT. We shall see whether alliances can avoid internal squabbling, disagreements on desired time patterns of net revenues, and technical difficulties in network design and interconnection.

Despite potential problems with alliances, business combinations will continue to seek ways to respond to commercial opportunities. This cascade of gaining footholds carries into other markets, presses other companies, and affects other customers. The end result is a global rivalry that drives investments in local infrastructure, which companies can then use to economically serve local customers. If this vision is correct, customers will benefit from greater choice and lower costs.

\section{Terms and Conditions of Interconnection ${ }^{6}$}

6. For purposes of this paper, "interconnection" includes physically connecting networks, one service provider carrying another service provider's traffic, co-locating telecommunications equipment on another providers' premises, and leasing network facilities. "Leasing network facilities" is sometimes called purchasing or leasing unbundled network elements (UNEs) such as local lines, switches, and lines between switches. "Terms" refers to all non-price aspects of interconnection, such as allowed points of interconnection (POIs) and the settlements process. "Settlements process" refers to the payment system by which money from retail customers is distributed among service providers and by which service providers compensate each other for interconnection services. 
The role of the state regulator in the decision-process is another issue that warrants attention Witkind and Zearfoss (1996),. Were prices established by regulatory in the traditional hearing process or were they privately negotiated and then "accepted" by regulators? Alternatively, was some alternative dispute resolution mechanism utilized, with regulators serving as mediators or as arbitrators? Alternative Dispute Resolution (ADR) refers to substitutes for litigation as way of establishing rules or outcomes. ADR procedures can promote timely decisions, reduce contention, save resources and/or influence outcomes. It is possible that the dispute resolution process was as important as the nature of regulation (price cap vs. ROR).

An alternative to the Lehman-Weisman explanation is that pure price caps are simply be part of a general pro-entry policy because pure price caps removes the opportunity for cost shifting. Also, it could also be argued that it is unreasonable for companies or regulators to assume that the adoption of pure price caps implied that no other policies would ever change. Indeed, the incumbent local exchange carriers (ILECs) in the US wanted price cap regulation to be mandated in the Act, but withdrew the proposal when it appeared that state PUCs would consider it an infringement on their jurisdictional responsibilities.

Given the complexity of the issues associated with partial deregulation and industry restructuring, we can expect regulators to continue to explore alternative mechanisms of adjudication:

Exceptional customer service is at least in part due to the ability of the utility to resolve disputes with suppliers/competitors and customers quickly. If the disputes are not resolved promptly, this could create an obstacle to the completion of transactions. One possible fallout could be an increase in the business failures of new market entrants. In the new era of regulation, it will be critical for disputes to be resolved expeditiously. (Butler, Pugh, and Cutting, 1996)

Stimulating greater responsiveness to customer needs and providing greater incentives for cost containment are the two driving motivations behind replacing regulation with competition. So ADR procedures are likely to become more important in the future. Timely intervention allows the process to deal with non-issues that might be thrown up as roadblocks by some parties. More important, it allows complicated issues to be addressed in a relatively non-adversarial setting. The interests of the parties may differ, but the resolution of technical issues can sometimes open up the possibility of win-win negotiations -- if regulatory and corporate opportunism can be avoided

Barker, Tenenbaum and Woolf (1997) distinguish between governance and regulation in the context of conflict resolution within new electricity power pools. "Governance is the process by which decisions get made, implemented and enforced-it is internal to the pools [or networks]. In contrast, regulation is how governments review and change the decisions of pools-it is external to pools [or telecommunications networks]." (p. v) In their description of decisionmaking models, they note the problems associated with alternative governance mechanismssince these involve different voting schemes, different approaches for representing stakeholder interests, and a variety of enforcement mechanisms. They argue that backstops (or appeals procedures) for pool governance are inevitable. 
replaced by lower prices), although Uganda and Columbia could be seen as having something in the spirit of the Baumol-Willig rule." (Jamison, 1998c).

The survey found prices similar to reports from Solomon Brothers the EU, but quite different from the Ovum report sent to Oftel. The difference between the Ovum report and these other reports is that Ovum pulled all forms of domestic interconnection, including interconnection for long distance access in the US, into a single comparison. All other reports focused only on interconnection for local network competition.

Within the U.S., some interesting cross-state patterns raise concerns regarding regulatory opportunism. To encourage competition, retail services are being partitioned into unbundled network elements (UNEs). State regulatory commissions have the authority to set prices for UNEs through arbitration and other regulatory proceedings either when the interconnecting companies disagree or when the regulator is concerned that the agreement might be contrary to the intentions of the Act. This policy raises potential concerns in conjunction with other policies, such as the choice of price caps vs. rate of return on rate base regulation (RORR). Lehman and Weisman (1998) examined the determinants of the average unbundled loop rate. They found the following: "The statistical evidence from these arbitrations suggests that regulators adopted more liberal competitive entry policies (i.e., lower prices for UNEs) in jurisdictions with pure price cap regulation in comparison with jurisdictions operating under traditional RORR" (p. 7). The average unbundled loop rate was also positively (significantly) related the FCC proxy cost (based on the cost/pricing methodology). Although the FCC order applying the proxy values has been vacated by the $8^{\text {th }}$ Circuit Court, these proxy costs appear to be utilized in state arbitration decisions.

Lehman and Weisman observe that regulators in price-cap jurisdictions are establishing lower entry barriers than those in RORR jurisdictions, all else equal. They conclude that such regulatory behavior reflects incomplete contracting--because regulators are circumventing the price cap commitment (which places firms at risk if they cannot meet cost-containment objectives). Firms agree to the terms of the price cap regime in order to gain flexibility--as they face sharper incentives for cost containment. Regulators then appear to be altering the rules of the game by systematically encouraging entry to a greater extent than where cost-of-service drives retail prices. In Lehman and Weisman's view, instead of reaping rewards from service innovations and productivity advance, incumbent providers may not have a "reasonable opportunity" to recover prudently-incurred costs. UNEs might be set below incremental cost, encouraging uneconomic entry and reducing incumbent profits.

However, the Lehman and Wiesman study needs to be extended to address other important issues, and to consider alternative explanations. Issues that should be addressed include the effects of the sequence of agreements and the role of the regulator in the decision process. The sequence issue is worthy of investigation to gauge the role of demonstration effects across states. To what extent do precedents in one jurisdiction affect the price of unbundled loops for the same incumbent in another state? Do agreements in one region affect agreements in others? Finally, does the strategic behavior of both incumbents and entrants lead to the targeting of particular states. Modeling the process and testing for causation represent important tasks for researchers. 
Telecommunications Act of $1996^{12}$ targets customers. This means that the subsidy can go to any eligible service provider that the customer chooses. To be eligible, the relevant state Public Utility Commission (PUC) must find that the service provider offers the services targeted by the federal universal service support mechanisms throughout the area using at least some of its own facilities and advertises these services using media of general distribution. ${ }^{13}$

There are two USO providers in the UK: British Telecom (BT) and, in Hull, Kingston Communications (KC). These companies are obligated to provide voice telephony services to customers even when it is uneconomic to do so. The UK Office of Telecommunications (OFTEL) undertook an investigation of the costs that these obligations impose on BT and $\mathrm{KC} .{ }^{14}$ OFTEL's consultant, Analysys, identified two aspects of BT's and KC's USOs that create USO costs: the cost of provision in uneconomic areas and the cost of provision to uneconomic residential customers in all other areas. ${ }^{15}$ In considering how to fund these USOs, OFTEL concluded that it is necessary to deduct USO benefits from USO costs so as not to advantage BT and KC. Specifically, OFTEL has stated that BT and $\mathrm{KC}$ might receive commercial advantage or financial benefit in the form of: ${ }^{16}$

enhancement of corporate reputation

marketing and brand recognition

information on how customers use the telephone

benefits associated with customer life cycles

benefits associated with ubiquity

the avoidance of loss of business through poor image and loss of trust due to disconnecting or discouraging subscribers

avoidance of the costs of disconnection, and minimization of planning costs.

Analysys estimated that the annual financial cost of serving uneconomic residential customers and uneconomic areas is between $£ 58$ million and $£ 89$ million for BT, and between $£ 0.39$ million and $£ 0.41$ million for KC. Taking into consideration the benefits, the net costs for BT are between $£ 4$ million and $£ 25$ million, or between $£ 9$ and $£ 40$ million depending on the interpretation of the USO. For KC, the net cost is approximately $£ 400,000$. Based on these estimates, OFTEL decided that the net costs of USOs are sufficiently small to merit no USO subsidy. ${ }^{17}$

Australia is now into its second estimate of net costs of Telstra's USOs. Telstra is the only USO provider in Australia. In its first estimate in 1989, Austel, the regulator at the time, examined

12. Pub. L. No. 104-104, 110 Stat. 56. The 1996 Act amends the Communications Act of 1934, 47 U.S.C. $\S \S 151$ et seq. (Act). Hereinafter, all citations to the Act and to the 1996 Act will be to the relevant section of the United States Code unless otherwise noted.

13. 47 U.S.C. $\S \S 214(\mathrm{e})$.

14. Office of Telecommunications, Universal Telecommunications Services: A Consultative Document on Universal Service in the UK from 1997 (December 1995).

15. Analysys, Final Report for Oftel: The Costs, Benefits and Funding of Universal Service in the UK (July 19, 1995).

16. OFTEL(1995)

17. Office of Telecommunications, Universal Telecommunications Services: Proposed arrangements for Universal Service in the UK from 1997 (February 1997). 
Given the technical nature of disputes, a specialized board can have both the expertise and flexibility necessary to reach decisions in a timely manner. It is possible that industry committees or boards could achieve consensus on a wide range of interconnection issues - but regulatory oversight would still be desired. Barker, Tenenbaum, and Woolf conclude that a twotier approach to governance is probably preferable to pure collective self-governance. Thus, an independent board can make a binding decision in the event of non-consensus or unreasonable delays. Such a board combines flexibility with expertise (and a detailed knowledge of the grid). It ought to have the power to ensure that disputes are not "bottled up" in a committee. In their model, the sector regulator serves as a point for the appeal of decisions by the technical board, should the need arise. Vertically-integrated incumbents network operators and entrants (buying network services from incumbents) have incentives to limit retail competition.

So regulators have a role in determining the terms and conditions of interconnection. The policy question is how that role is performed and whether particular negotiation or mediation processes are less conducive to regulatory (and/or corporate) opportunism.

\section{Universal Service as a Dimension of Performance ${ }^{8}$}

Telecommunications market liberalization and privatization are prompting many countries to revise their Universal Service Obligation (USO) policies. When revising USO policies, governments must resolve the issue of the amount of money needed to fund the USO, which was not an issue under the traditional cross-subsidization schemes within the context of a monopoly supplier. Two major types of USOs need to be considered: historical USOs and ongoing USOs. Historical USOs are those that have been fulfilled in the past and that may not have been fully compensated. Ongoing USOs include ongoing or future requirements to price some services at unprofitable levels, to maintain uneconomic levels of infrastructure in order to stand ready to serve, and to utilize a non-optimal technology in order to promote social goals, such as community or economic development.

There are two basic paradigms for designating USO providers. ${ }^{9}$ Most countries have a single USO provider in an area. Only this provider can obtain USO subsidies. Governments in Australia and the UK designated the incumbent service providers as the USO providers. Chile used a competitive process to select USO providers. ${ }^{10}$ In contrast, the US will have multiple USO providers in an area. ${ }^{11}$ In the US, the new subsidy framework under the

8. This draws upon material in Jamison (1997b).

9. Mark A. Jamison, "Estimating Costs for Universal Service Obligations," Telecommunications Journal of Australia 47(1): 51-58, 1997.

10. Björn Wellenius, "Extending Telecommunications Service to Rural Areas - The Chilean Experience," Private Sector 9: 35-38, (December 1996).

11. This may not be true for all USOs. The obligations in the US may not be symmetric among all competing USO providers. In the past, some regulators have required incumbent local exchange carriers (ILECs) to maintain an uneconomic level of infrastructure in order to stand ready to serve or to place an unremunerative technology in order to facilitate community or economic development. Continuation of these obligations without either the regulator or the market placing a symmetric burden on new entrants, will make this portion of the US USOs be of the single-provider type. 
The FCC has determined that proxy cost models will be used to estimate forward-looking economic costs. ${ }^{23}$ A proxy cost model is an engineering process model that estimates costs of a representative company as opposed to a specific company. Initially, three proxy cost models were considered: (1) BCPM; (2) the Hatfield Model, developed by Hatfield Associates; and (3) TECM developed by Ben Johnson Associates, Inc. ${ }^{24}$ The models varied in their engineering assumptions and input values, such as depreciation and cost of capital. The FCC dropped consideration of the TECM because it could not provide nationwide estimates of USO costs.

The FCC is in the midst of deciding details of its proxy cost model should work, with a target implementation data of January $1,1999 .^{25}$ So far the FCC has decided that a proxy cost model should meet the following criteria: ${ }^{26}$

1. The technology assumed must be the least-cost, most efficient, and reasonable technology for providing the supported services that is currently being deployed. Network topology, line counts, and average loop lengths should match ILECs' existing networks.

2. Any network function or element must have an associated cost.

3. Only long-run forward-looking economic cost may be included. All costs must be treated as variable and avoidable. The costs must be based upon the current cost of purchasing facilities and equipment rather than list prices.

4. The rate of return must be either the authorized federal rate of return on interstate services, currently 11.25 percent, or the state's prescribed rate of return for intrastate services.

5. Economic lives and future net salvage percentages used in calculating depreciation expense must be within the FCC-authorized range.

6. The proxy model must estimate the cost of providing service for all businesses and households within a geographic region.

7. A reasonable allocation of joint and common costs must be included.

8. The proxy model and all underlying data, formulae, computations, and software must be available to all interested parties. All underlying data should be verifiable, engineering assumptions reasonable, and outputs plausible.

9. The proxy model must include the capability to examine and modify the critical assumptions and engineering principles.

10. The proxy model must deaverage support calculations to the wire center serving area level at least, and, if feasible, to even smaller areas.

Regulators' use of cost models in this context is unique in telecommunications regulatory history. Regulators have traditionally relied upon companies for cost estimates or tied costs to specific company's operations, as in the case of using embedded costs. Regulators' control of cost models raises an issue of credibility. Two FCC cost model requirements raise this issue. First, the FCC requires that all underlying data, formulae, computations, and software are to be

23. Federal Communications Commission, Federal-State Joint Board on Universal Service, CC Docket No. 96-45, Report and Order, FCC 97-157 (rel. May 8, 1997), par. 6 (Order).

24. U S West, Sprint, and Pacific Bell sponsored BCPM. The Hatfield model was sponsored by AT\&T and MCI. There have been several different versions of the Hatfield model. The New Jersey Ratepayer Advocate sponsored the TECM.

25. FCC, Order, par. 2.

26. FCC, Order, par. 250. 
both embedded, fully allocated costs and forward-looking incremental costs of USOs. Austel chose the incremental cost method and found costs of $\mathrm{A} \$ 237$ million for general USOs, $A \$ 8$ million to $\mathrm{A} \$ 10$ million for concessions to charitable organizations and the disabled, $\mathrm{A} \$ 4.5$ million for emergency service, and A $\$ 48$ million for telephone rentals to pensioners. ${ }^{18}$

Currently, the Australian Communications Authority (ACA, formerly Austel), is finalizing an engineering cost model for estimating net USO costs. ${ }^{19}$ The three telecommunications carriers in Australia are funding the model development, but the developer (Bellcore) answers to Austel. The model will determine the net incremental cost (using LRIC principles) of providing 'standard' telephone services and payphones. Revenues and costs from providing 'non-standard' services are excluded. All carriers in Australia will help fund the subsidy by making a levy payment to Telstra on the basis of their share of total industry 'eligible revenue' for the same financial year. There likely will be four different costing groups: (1) very small exchanges will be costed on a whole of exchange basis; (2) larger exchanges will be broken down into two types of areas and costed separately -- rural townships where costs per customer tend not to vary too much within an individual township and rural townships where net costs can vary significantly; (3) payphones; and (4) radio and satellite customers. ${ }^{20}$

Chile has open competition in telecom markets. But in $1995,10 \%$ of population had no access to a telephone. To remedy this, the government identified unserved areas and estimated potential profitability. It informed carriers of those that appeared could be profitable and auctioned subsidies for the apparently unprofitable areas. For the auction, the government set maximum subsidies and price caps for each area. The auction was conducted in 1995-96. In areas where there was competitive interest, subsidies were bid to zero. In areas with no or only token competition, subsidies were bid at or near maximum, or not bid at all. Prior to the auction, the government had estimated the necessary subsidy would be US $\$ 4.2$ billion. The auction resulted in actual subsidies of US $\$ 2.2$ billion granted, although not all of the areas in the US $\$ 4.2$ billion received bids. ${ }^{21}$

In the US, the Federal Communications Commission (FCC) and state PUCs are developing methods for estimating net USO costs that will be portable among eligible carriers. For the FCC, estimating these net costs involves four steps: (1) Estimate the forward-looking economic costs of providing universal service for rural, insular, and high cost areas; (2) Establish a nationwide revenue benchmark calculated on the basis of average revenue per line; (3) Calculate the difference between the forward-looking economic cost and the benchmark; and (4) Estimate the federal support at 25 percent of that difference. ${ }^{22}$

18. Australia Bureau of Transport and Communications Economics, The Cost of Telecom's Community Service Obligations (Canberra, 1989).

19. An engineering process model estimates costs by constructing telephone networks of specific technologies and with specific levels of productivity.

20. Interviews with Neill Whitehead, ACA, 1997.

21. Wellenius (1996).

22. Federal Communications Commission, Federal-State Joint Board on Universal Service, CC Docket No. 96-45, and Forward-Looking Mechanism for High Cost Support for Non-Rural LECs, CC Docket 97-160, Further Notice of Proposed Rulemaking, FCC 97-256 (rel. July 18, 1997), par. 1 (FNPRM). 
and implemented so that neither past nor future social obligations prevent firms from responding to new commercial and technological opportunities.

How can academic researchers contribute to an informed debate that addresses these complex issues? There are at least two roles: improving theory and translating principles into practice. The first role helps us understand the nature of fundamental economic trade-offs. Better models enable analysts to identify key parameters for empirical research. The second role requires more interaction with those responsible for developing and implementing policy. Both public and private decision-makers need to be able to take theoretical results and utilize the principles in practice. Not everyone can "fight fires", some must develop fire-fighting equipment. Conversely, not everyone should be developing fire-fighting equipment.

Some PURC activities are devoted to "fighting fires" and training senior fire-fighters--those responsible for creating sustainable regulatory frameworks. The PURC/World Bank International Training Program on Utility Regulation attempts to communicate fundamental principles that can be applied within a very diverse set of national situations. At the same time, we try to initiate an on-going educational process for commission staff. No one has all the answers. What is important is that these independent regulatory agencies begin asking the right questions and developing the conceptual frameworks and information required for addressing critical issues.

One attendee from a developing country was that nation's first energy regulator. He understood the pivotal role he would be playing in the years ahead, and the importance of a sound regulatory framework for capital attraction and the sustainability of his new regulatory institution. He sat each morning in the front row, following the presentations carefully and asking intelligent questions of the speakers. Often he would comment on particular observations-sometimes supporting the generalization and sometimes qualifying the point by recognizing other trade-offs. His eloquence and insights were acknowledged by all.

Since we sat in the front with the other speakers, we noticed that he had two notebooks. Sometimes he would write a paragraph in one, and after hearing other ideas developed by the speaker, he would dig into his briefcase and write in another notebook. Near the end of the two weeks, one author's curiosity could not be contained. He asked the participant about the two notebooks. The regulator responded by holding out of the notebooks: "One is for useful ideas." That gave the author some comfort. However, he was still unsure about the second notebook. When asked, the regulator said, "The other is for interesting ideas." As educators who try to translate principles into practice, we understood the distinction quite well. He wanted to return to his homeland with an agenda for his staff. He wanted to apply some the ideas and principles immediately. However, he also recognized that some of the ideas still needed to germinate some more. The particular conceptual framework from a session might be interesting (and show promise), but it needed more time before it could be applied. Or, the idea provided a sound intellectual basis for some development (such as incentive regulation), but that background information could not be applied in the present institutional environment.

At the national level, it is clear that each participant draws different lessons from the fifty sessions in the course. The regulators and executives find some ideas about our fire-fighting 
available to all interested parties for review and comment, and all underlying data is to be verifiable. Second, the FCC requires that the model include means by which regulators can examine and modify critical assumptions and engineering principles, including the cost of capital, depreciation rates, fill factors, input costs, overhead adjustments, retail costs, structure sharing percentages, fiber-copper cross-over points, and terrain factors. These recommendations are in line with the policies proposed in this paper for not allowing companies to manipulate the cost model. However, the ease of changing critical assumptions in the model places an additional burden on policy makers to ensure that parties or regulators do not strategically use the model.

Such manipulation has been the case in Chile where proxy models are used to estimate electricity distribution costs. Distribution costs are estimated every four years. The procedure involves the calculation of the costs of an efficient firm and then setting prices to cover these costs. Both the industry and the regulator (CNE) calculate costs of an efficient firm. The industry's estimate is given a weight of $33 \%$ and the CNE's estimate is given a weight of $67 \%$. Even though this approach is supposed to make cost studies relatively objective and technocratic, the fixed-weight averaging creates incentives for strategic behavior on the parts of the industry and CNE. Both have an incentive to bias their own estimate, subject to what they think the other will estimate, so that the weighted average achieves their objectives. As a result, discrepancies between the industry's and CNE's estimates have exceeded $50 \%$ in some cases. ${ }^{27}$

Regulators should use reality checks to verify that their model assumptions will have the intended market and universal service effects. One way this can be done is by comparing their model's results against actual company operations. This is not to say that actual company operations are the "correct answer." Indeed, part of the discussion above demonstrated why it is inappropriate to base USO subsidies on actual company operations. However, checking model results against multiple company operations removes the perverse incentives and may, in some circumstances, remedy problems with embedded cost allocations. It is clear that policy issues associated with USOs will continue to stimulate theorists to develop new models for calculating the costs and benefits of network industries. The issues will create opportunities for improved quantitative analyses as well.

\section{A Research Agenda: Concluding Observations ${ }^{28}$}

We have outlined three areas where translating principles into practice can improve performance in telecommunications. Strategic alliances can facilitate entry and create multiple centers of initiative in this dynamic industry. However, for competition to become actual (rather than potential), the terms and conditions of network interconnection need to be determined in ways that promote both an efficient configuration of suppliers and provide incentives for innovative investments. Finally, funding mechanisms for Universal Service Obligations must be developed

27. E. Bitran and Pablo Serra, "Regulatory Issues in the Privatization of Public Utilities: The Chilean Experience," The Quarterly Review of Economics and Finance 34 (1994): 179-197; and Warrick Smith and Michael Klein, Infrastructure Regulation: Issues \& Options for East Asia, The World Bank (December 1994).

28. Partly adapted from Berg (1998). 
equipment useful, and some ideas interesting. We want the overall experience to reinforce the importance of being open to new ways of handling regulatory oversight responsibilities. We want good theory to be applied so that public policies towards these important sectors will yield benefits to both the suppliers and customers.

Sector regulation is a relatively new activity for most countries. Government intervention via ownership or ministerial decrees has characterized these industries. Now, independent regulatory commissions and antitrust authorities are implementing national policies towards monopoly segments of infrastructure industries. The image of a new cadre of bureaucrats might make some analysts nervous. However, the images that remain with us are far different from the stereotypes depicted in newspapers: faceless, power-hungry individuals who reduce efficiency through the issuance of arbitrary rules.

Attendees were aware of the poor reputations of many people in government agencies. They wanted to avoid getting into the trap of protecting their jobs at the expense of productive activity elsewhere in the economy. Thus, we observed a sense of professionalism throughout the course. Individuals with diverse technical training were looking for specific skills and improved understanding of how alternative processes affected industry performance. Attendees sought approaches to decision-making that would improve the lives of ordinary people in their countries. They understood the links among market reform, credibility and capital costs, incentives for cost containment, service quality, competition, rate structures, and the design and management of regulatory processes. In addition, we think that they were realistic in terms of recognizing institutional constraints faced at home. Regulators knew that their agencies needed to establish a track record that would justify the trust others were placing in them. Executives in attendance recognized the potential fragility of new institutions and the importance of identifying procedures that promoted win-win outcomes. The experience has made us somewhat optimistic regarding the positive role that regulatory institutions can play in promoting development.

Customer needs and the economics of the business have changed dramatically since business models and products (voice telephony) initially attracted the attention of public policy-makers. However, regulation and the lack of competition have kept the business model and product from changing. As a result, current company structures are inefficient. Now that we are allowing competition, companies need to align themselves according to the new business fundamentals. This includes getting the right mix of local properties and vertical integration. Companies that do it right will be more efficient and have products that match what customers want to buy. Companies that do it wrong will either limp along, be bought, or go out of business. No one knows what the best constellation of products, reliability, and user-support will be in the future-the evolutionary process of Schumpeterian competition will force suppliers to discover what customers are willing to pay for.

All we know is that tomorrow's successful companies are likely to look quite different from today's companies. The new companies will have different geographic, product, and customer markets. Getting from today to tomorrow will involve combinations of mergers, takeovers, divestitures, new start-ups, and bankruptcies. No single way is best. Given how far companies have to go and the short time to get there, we would expect more re-combinations of existing 
businesses than new business creation and business destruction. Customers will benefit from this if companies are allowed to select efficient paths.

Policy-makers need to remember that the new rivalry in telecommunications is more intense than is captured in our traditional models of competition. Telecommunications markets are not like fast food markets where essentially identical companies stand toe to toe and slug it out. Telecommunications companies are diverse in their strengths, products, markets, and market contacts. This diversity enhances market pressure. For the same number and types of companies in a market, you get more competitive rivalry in telecommunications markets than in fast food markets. Also, because some telecommunications markets are global and national, we are more likely to get local infrastructure competition when companies vertically integrate and reach across multiple geographic markets. In the process, issues associated with mergers, interconnection, and Universal Service Obligations will continue to provide fertile fields for research that is useful and research that is interesting.

\section{Bibliography}

Berg, Sanford V. (1998), "Priorities in market reform: regulatory structures and performance," Pacific and Asian Journal of Energy, 7(2): 89-101.

and R. Dean Foreman (1996), "Incentive Regulation and Telco Performance: a Primer, Telecommunications Policy, Vol. 20, No. 9, pp. 641-652.

and Jinook Jeong (1991), "An Evaluation of Incentive Regulation for Electric Utilities," Journal of Regulatory Economics, Vol. 3, No.1, March, 45-55.

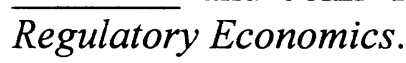

and John Tschirhart (1995), "A Market Test for Natural Monopoly," Journal of

Butler, Melinda, Shedrick Pugh, and John Cutting (1996), "Administering Alternative Dispute Resolution: the Role of Regulatory Commissions," Bureau of Research and Policy Analysis, Florida Public Service Commission.

Harris, Robert G. and C. Jeffrey Kraft, (1997), "Meddling Through: Regulating Local Telephone Competition in the United States," Journal of Economic Perspectives, Fall, 11:4, 93112.

Hausman, Jerry A. (1997), "Valuing the Effect of Regulation on New Services in Telecommunications," Brookings Papers on Economic Activity: Microeconomics.

Jamison, Mark A. (1997a) "Estimating Costs for Universal Service Obligations," Telecommunications Journal of Australia 47(1):51-58. 
Jamison, Mark A. (1997b), "Principles for Estimating Universal Service Costs," PURC Working Paper.

(1998a), "Emerging Patterns in Global Telecommunications Alliances and Mergers," Industrial and Corporate Change (forthcoming).

Working Paper.

(1998b), "Has the US had Enough Telecommunications Mergers?" PURC

(1998c), "International Survey of Interconnection Policies: First Updated

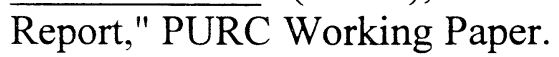

Working Paper.

(1998d), " Telecommunications Mergers Can Work for Customers," PURC

Lehman, Dale E. and Dennis L. Weisman (1998), "The Political Economy of Price Cap Regulation, Kansas State University Working Paper.

Levy B, Spiller P. 1994. The institutional foundations of regulatory commitment: a comparative analysis of telecommunications regulation. The Journal of Law, Economics and Organization 10(2): 201-246

Levy B, Spiller P. 1996. Regulations, Institutions, and Commitment: Comparative Studies of Telecommunications. New York: Cambridge University Press.

Ware, Harold (1998), "Competition and Diversification Trends in Telecommunications: Regulatory, Technological., and Market Pressures," ," Journal of Regulatory Economics. 13-1, January, 59-94.

Winston, Clifford and Robert W. Crandall (1994), "Explaining Regulatory Policy, Brookings Papers on Regulatory Policy: Microeconomics, 1-49.

Witkind, Vivian and Nancy Zearfoss (1996), "State Commission Mediation and Arbitration of Interconnection Agreements: Procedures and Status Under the Telecommunications Act of 1996, NRRI. 
